\title{
Making the least active pay: A simulation of rewards and penalties under Demand Side Participation programs
}

Published as Torriti J, Leach M (2012). Making the least active pay: A simulation of rewards and penalties under demand side participation programs. International Journal of Green Energy 9(7):584-596 01 Oct 2012

\begin{abstract}
The orthodox approach for incentivising Demand Side Participation (DSP) programs is that utility losses from capital, installation and planning costs should be recovered under financial incentive mechanisms which aim to ensure that utilities have the right incentives to implement DSP activities. The recent national smart metering roll-out in the UK implies that this approach needs to be reassessed since utilities will recover the capital costs associated with DSP technology through bills. This paper introduces a reward and penalty mechanism focusing on residential users. DSP planning costs are recovered through payments from those consumers who do not react to peak signals. Those consumers who do react are rewarded by paying lower bills. Because real-time incentives to residential consumers tend to fail due to the negligible amounts associated with net gains (and losses) for individual users, in the proposed mechanism the regulator determines benchmarks which are matched against responses to signals and caps the level of rewards/penalties to avoid market distortions. The paper presents an overview of existing financial incentive mechanisms for DSP; introduces the reward/penalty mechanism aimed at fostering DSP under the hypothesis of smart metering roll-out; considers the costs faced by utilities for DSP programs; assesses linear rate effects and value changes; introduces compensatory weights for those consumers who have physical or financial impediments; and shows findings based on simulation runs on three discrete levels of elasticity.
\end{abstract}

\section{Keywords}

Demand Side Management; Demand Side Participation; Pricing Elasticity; Tariffs 


\section{Introduction}

High peak demand on the electricity grid creates significant impacts on system costs because of the need for higher marginal cost generation, higher cost system balancing and increasing grid reinforcement investment. Demand Side Management programs use rates, incentives and other strategies to help better manage electricity use during periods of high peak demand (Bilton et al., 2008). Those Demand Side Management initiatives involving direct participation from the consumer side, which in this paper we call 'Demand Side Participation' (DSP) programs, can in principle bring about significant reductions in electricity prices, as demand-driven shifts of demand during peaks could reduce marginal costs (Faraqui, 2005). In practice, DSP programs can only work upon two conditions. First, DSP can only operate in the absence of asymmetries of information. A constant exchange of information between the provider and the consumer via two-way communication systems should operate under price sensitive technologies. The roll-out of smart metering technology aims to reduce asymmetries of information by covering large portions of consumer population and ensuring immediate access to information regarding consumption (Torriti et al, 2010). Second, the demand side should respond to the signals inputted by the provider. There are various ways of fostering active demand participation, namely through changes in price structures, information programs and incentives. This paper focuses on the latter, focusing on rewards and penalties for the consumers.

The extensive theoretical literature on planning Demand Side Management agrees that one major reason why DSP programs are not effective is because of the absence of electricity providers' incentives to use DSP (Wirl, 1995; Fisher, 2005; Faruqui et al., 2010). The existing literature is based on the concept that providers may see DSP programs as sub-optimal due to the losses associated with reductions in demand which exceed gains associated with marginal decreases in generation costs and imports. The orthodox rationale is that losses from capital costs, installations and planning DSP should be recovered under financial incentive mechanisms such as Cost Recovery Mechanisms, Lost Revenue Mechanisms. The case of massive smart metering roll-out in the UK, means that suppliers have already faced capital costs (about $£ 340$ per household) and recouped them from customers through higher bills or upfront fees. 
We ensure that planning costs of DSP programs are still recovered so that providers make up for such costs by receiving payments from consumers for not reacting to price signals. In addition, those consumers who proactively engage in shifting their loads and significantly react to price signals will be rewarded by paying less for their electricity consumption. Because real-time rewards to consumers tend to fail due to the negligable amounts associated with gains (and losses) for a single consumer (Dulleck and Kaufmann, 2004), in the approach presented here, the regulator determines cumulative benchmarks which are matched against responses to price signals.

This paper commences with a brief overview of existing financial incentive mechanisms for DSP (Section 2). It presents a price mechamism aimed at fostering DSP programs (Section 3). It considers the costs faced by utilities for DSP programs (Section 4) and rate effects and value changes (Section 5). Since the objectives should be set in a way that proportionally penalises non-active consumers, the mechanism should guarrantee that consumers who have any sort of impedement to responsiveness will not pay excessively for their performance (Section 6). Findings based on simulation runs on three levels of elasticity are presented (Section 7). The conclusion reflect on the implications and challenges associated with the proposed mechanism (Section 8).

\section{Financial incentive mechanisms for providers}

Existing financial mechanisms by regulators to incentivise DSP programs focus almost exclusively on providers. It is assumed that providers will have to pay for the absence of technological investments in DSP. The idea behind the financial schemes in place in the United States, Canada, Australia and India is that losses from capital costs, installations and planning DSP should be recovered under mechanisms such as cost recovery mechanisms, lost revenue mechanisms and shared savings incentive mechanisms based on performance.

Cost recovery mechanisms are designed to eliminate the business incentive to underspend on DSP programs. They allow providers to recover the capital and 
installation costs. The utilities costs for DSP are usually "expensed," approved by regulators and sometimes amortised over several years. Interest is charged on under or over- recoveries. Because under cost recovery mechanisms the providers costs are amortised over several years, the economic significance of load shifting is lost. In other words, the behavioural learning on the consumer side is very limited.

Lost revenue mechanisms pay providers back for the direct losses that they experience due to decreases in electricity sold. Lost revenues associated with reductions in total amounts of sold electricity are partly offset by a reduction or avoidance of variable costs -e.g. the cost of fuel for power plants. The typology of opportunity costs often included in lost revenue mechanisms include recovery of all of the revenues that providers would have benefited from had they not promoted DSP programs. Lost revenue mechanisms are designed to make DSP revenue-neutral and eliminate the incentive to minimise savings from DSP. This leaves the provider financially indifferent to the level of DSP achieved. A practical example of lost revenue mechanism can be exemplified through the Lost Revenue Adjustment Mechanism, a means to compensate for lost revenues in Canada. In a given year, the provider calculates the amount of volume or kWh losses due to its own DSP programs. This must be calculated net of any efficiency trends occurring independently of DSP, since sales losses due to other factors would have been experienced anyway.

Lost revenue mechanisms are designed to make DSP revenue-neutral and eliminate the incentive to minimise savings from DSP. This leaves the provider financially indifferent as to the level of DSP that is achieved. The provider gets reward for its DSP losses. If services delivered go down as a result of DSP activities, all other things being equal, rates will go up so that costs may be recovered. This means that all consumers pay for lack of responsiveness. Instead, it would be much preferable if only the least responsive consumers had to pay.

Shared Savings Incentive Mechanisms are designed to provide rewards to utilities based on the effectiveness of socially beneficial DSP. These mechanisms can compensate for energy savings associated with DSP by making it possible for the provider to share the consumer net benefits from DSP programs. In principle, penalties for underperformance can also be part of a Shared Savings Incentive 
Mechanism, but have not been implemented. This creates a business case for sustainable DSP initiatives that promote energy efficiency on an evolving, adaptive, multi-year basis. A pre-condition of Shared Savings Incentive Mechanisms is that the regulator determines DSP target levels on providers. This can represent a forecasting problem under different (e.g. temperature) conditions that might induce peak loads. For instance, a share or percentage of actual DSP net benefits over the target level determined by the regulator can be apportioned to the provider in the form of a positive rate adjustment. In other words, the aim of Shared Savings Incentive Mechanisms is to remunerate a provider to achieve more than the targets approved by the regulator. However, it is difficult to make incentives dependent upon objective verification.

In addition to the points raised above for each of the mechanisms, at least three common planning problems can be related to all three mechanisms. First, they all focus on network and generation capacity recovery rather than consumer learning. Incentives concentrate mostly on recuperation of costs on the provider side rather than ensuring that consumers improve their demand participation. Second, in all three mechanisms establishing the level of incentives for providers is challenging for the first year. Third, they all build on the hypothesis that capital costs associated with technological investment have to be met by providers. The model put forward in this paper transcends these problems by: (i) considering consumer performance in terms of demand participation; (ii) developing a mechanism to determine the level of rewards and penalties based on DSP performance; and (iii) excluding some technological investment costs from the mechanism. The third point suits national roll-out plans, where the capital costs of smart meters are recouped from consumers through higher bills or upfront fees. In other words, rewards and penalties can be based on consumer responses to price signals and yet ensure that providers planning costs are recovered.

\section{Reward/penalty mechanism}

The economic agents involved in the DSP mechanism are consumers, utilities and a regulatory agency. Time runs in a discrete sequence of periods indexed by the period unit $t$. There are $c$ consumers, producing $c$ different responses to price signals 
typically under high peak periods. We assume that the market where the mechanism is introduced is competitive, so consumers take prices as given. The regulatory agency has the power to allow changes in prices under DSP programs.

At the beginning of each period, benchmarks are established according to overall consumers' performance in the previous period. The benchmark $(B n)$ for the time $t$ is obtained as a result of performance for the previous period using level of reward/penalty $\alpha$ :

$$
\mathrm{Bn}_{\mathrm{t}}=\mathrm{Bn}_{\mathrm{t}-1}\left(1-\alpha_{\mathrm{t}}\right)
$$

If consumers overall reacted more frequently to price signals at the time $t$ - 1 , than at the time $t-2$, then $\alpha$ will increase for the next period $t$.

The level of $\alpha$, where $0<\alpha<1$, for one period is dependent on performance in the previous period, according to standard incentive model (Kahn, 2002), based on the following regulator's problem

$$
\alpha_{\mathrm{t}}=\max \left[\beta \% ; 1-\left(\frac{\text { Meas }_{\mathrm{t}-1}}{\mathrm{Bn}_{\mathrm{t}-1}}\right)^{\frac{1}{\mathrm{t}}}\right]
$$

where Meas $_{t-1}$ is the measured consumer responsiveness for the previous period, $B n_{t-1}$ is the benchmark for the previous period, and $\beta$ is the minimum number of responsive actions that consumers can undertake for the period $t$.

Each consumer will be faced with the choice to respond to price signals more frequently than the benchmark level in order to get rewards. If the consumer responds to price signals less frequently than the benchmark level the consumer will pay penalties.

The level of reward/penalty should be minimum $\beta \%$. The minimum number of responsive actions that one consumer can undertake in one year can be determined as percentage of continuous annual supply. Hypothtically, contingent valuation surveys can help both identify how much British consumers are willing to pay (WTP) and refine the parameters for determining the rewards/penalties ratio between for the 
baseline period. The WTP value can define the maximum number of responsive actions that one consumer can undertake in one year, as percentage of continuous annual supply. A related approach has been used to value distribution tariffs in the residential sector in Sweden (Bartusch et al, 2011; Bartusch et al, 2010). However, the actual use of contingent valuation for valuing changes in electricity tariffs may be problematic, as envisaged in studies using contingent valuation in order to value WTP for improving the quality of supply (Ajodhia et al, 2006); energy saving measures (Banfi et al, 2008); and renewable energy (Wiser, 2007; Nomura and Akai, 2004). The main problem with contingent valuation surveys relates to higher WTP disclosed by residential users when the public good is supplied through a collective scheme than when individual payment mechanisms -like the one introduced in this paper- are applied.

Each period $t$ consumers are rewarded or penalised according to their measured performance $\mathrm{Meas}_{c, t}$. For instance, if a consumer reacted 7 times to 11 price signals by the provider to reduce or shift loads, then Meas=0.63. Unitary reward/penalty parameters are set ex ante at the beginning of the year. Reward and penalty parameters are capped

$$
\operatorname{Min}\left(\alpha \_ \text {cap }\right) \leq \alpha_{\mathrm{c}} \leq \operatorname{Max}\left(\alpha \_ \text {cap }\right)
$$

in order to limit volatility of retail prices. For every $t$, the price-cap reflects the changes in rewards and penalties. The incentive system is funded through penalties paid by those consumers whose responsiveness targets are not met, and for the net difference between rewards and penalties, through adding an R-factor in the conventional price-cap formula:

$$
\text { price_cap }{ }_{\alpha}=\mathrm{RPI}-\mathrm{X} \pm \mathrm{R}_{\mathrm{c}, \mathrm{t}}
$$

where RPI represents the Retail Price Index and $X$ are the expected efficiency savings. The subtraction RPI-X represents the conventional price-cap formula (Sibley, 1989), whereas $R$ can be seen as the factor that varies ex post for each year $t$ based on measured responsiveness: 


$$
\mathrm{R}_{\mathrm{t}}=\sum_{\mathrm{c}=1}^{\mathrm{n}}\left(\mathrm{Bn}_{\mathrm{c}, \mathrm{t}}-\operatorname{Meas}_{\mathrm{c}, \mathrm{t}}\right) \times\left[\frac{\mathrm{C}_{\mathrm{gen}}}{8760}\right]
$$

Where $R_{t}$ is responsiveness factor for the period $t, C_{g e n}$ is the generation cost (in $\mathrm{hr} / \mathrm{kWh}), B n_{c, t}$ is the active demand participation benchmark set ex ante for each type of consumer $c$ for each year $t$. Consumer responsiveness is determined by Meas $s_{c, t}$ which is measured response activities for each type of consumer $c$ for year $t$ (in minutes).

The $R$ factor for the period $t$ is determined as a result of the sum of all benchmark levels minus measured consumer responsiveness multiplied by the provider cost of generation under DSP programs.

Thus far we have defined the basic equations for determining the objectives of responsivess for individual consumers (benchmarks), levels of rewards $\left(\alpha_{c}\right)$ and cap values $\left(\right.$ price_cap $\left._{\alpha}\right)$. The mechanism consists of price signals from the provider in case of peak loads, when $C_{g e n}$ is higher than usual at the time $t_{l}$. The signal is inputted through the DSP program $j$ to the consumer $c$ who decides whether to respond to it (in which case Meas $_{c, t}$ increases) or not (in which case Meas $_{c, t}$ decreases). Determining $C_{g e n}$ is vital in order to assess $\alpha_{c}$ as well the efficiency of the DSP programme according to the provider.

\section{Costs for providers}

This section investigates the cost of planning DSP programs attributable to each customer $c$ for not responding to price signals. How much each provider will spend can be determined as non-DSP cost of generation plus cost of DSP values

$$
\mathrm{C}_{\mathrm{gen}}=\sum_{\mathrm{c}} \mathrm{c}_{\mathrm{c}} \mathrm{G}_{\mathrm{c}}+\sum_{\mathrm{j}}\left[\left(1-\alpha_{\mathrm{j}}\right) \mathrm{d}_{\mathrm{uj}}\right] \mathrm{DSP}_{\mathrm{j}}
$$

where $G_{c}$ is the generation for consumer $c$ (expressed in $\mathrm{MW}$ ), $c_{c}$ is the generation cost for consumer $c$ (in $£ / \mathrm{MWh}$ ), $D S P_{j}$ are the energy savings associated with the DSP $\operatorname{program} j$ (in MW), $d_{u j}$ is the provider cost for the DSP program $j$ (in $£ / M W h$ ), and $\alpha_{j}$ is the percentage of provider cost consisting of rewards (e.g. monetary transfers) to participants in programme $j$. 
Equation (3) quantifies the generation cost which becomes necessary for consumer not responding to price signals $\left(\sum_{c} c_{c} G_{c}\right.$, which includes increasing loading cycles, start-up and shut-down costs of power systems), and the avoided savings from DSP with a $\%$ of provider costs consisting of rewards to participants $\left(\sum_{j}\left[\left(1-\alpha_{j}\right) d_{u j}\right]\right.$ $\left.D S P_{j}\right)$.

Equation (3) provides the level of cost to the provider of generation and DSP actions. It provides a simple and fair characterization of the dynamics for valuing generation. However, it ignores details with regards to temporal variability of loads, costs and generator availability. This is because some of the capital costs necessary for DSP technologies are already met via recouping costs of smart meters. Scale economies in DSP programs and non-linear heat rates are not taken into account. Complications associated with interaction between different DSP programs, energy-limited units and storage are not considered because they are not necessary for the purpose of this model, which is to show how changes in total value can be included in the reward/penalty mechanism (Decanio and Laitne, 1997).

In terms of generation costs, each provider is disposed to pay according to an $\alpha_{j}$ percentage to responsive consumers for programme $j$, as follows:

$$
\alpha_{\mathrm{j}}=\frac{\left(\text { Cgen }-\sum_{\mathrm{c}} \mathrm{c}_{\mathrm{c}} \mathrm{G}_{\mathrm{c}}\right) \sum_{\mathrm{j}}\left(\mathrm{d}_{\mathrm{uj}}\right) \mathrm{DSP}_{\mathrm{j}}}{n}
$$

where $n$ is the number of DSP programs implemented by the provider. Compared to the estimate of $\alpha_{c}$ made by the regulatory agency, the provider choice on $\alpha_{j}$ is characterised by cost minimisation constraints. While the regulator faces an effectiveness problem (i.e. maximising rewards and penalties, while keeping weak consumers safe), providers face an efficiency problem (i.e. finding the right level of rewards to DSP programs). How can these two different problems be reconciled?

Firstly, the responsiveness factor in Equation (2) should include the cost of generation faced by utilities of Equation (3) 


$$
R_{t}=\sum_{c=1}^{n}\left(B n_{c, t}-\operatorname{Meas}_{c, t}\right)\left[\frac{\sum_{c} c_{c} G_{c}+\sum_{j}\left[\left(1-\alpha_{j}\right) d_{u j}\right] D S P j}{8760}\right]
$$

Secondly, the two different levels of rewards should be made equal in order to calculate the appropriate level for the decision variable $G_{c}$. Hence, combining (1) and (4)

$$
\frac{\left(\text { Cgen }-\sum_{c} c_{c} G_{c}\right) \sum_{j}\left(d_{u j}\right) D_{j}}{n}=1-\left(\frac{\operatorname{Meas}_{c}^{\frac{1}{z}}}{B n_{c}}\right)^{\frac{1}{t}}
$$

All loads must be met either by normal generating power or additional generating power. For this reason the model includes the following demand constraints and upper bounds on the provider's decision variables $G_{c}$ and $D S P_{j}$ :

$$
\begin{aligned}
& \mathrm{D}=\sum_{\mathrm{j}} \operatorname{DSPj}+\sum_{\mathrm{c}} \mathrm{G}_{\mathrm{c}} \\
& 0 \leq \mathrm{G}_{\mathrm{c}} \leq \mathrm{cap} \quad \forall c \\
& 0 \leq \mathrm{DSP}_{\mathrm{j}} \leq \mathrm{D}^{*} \quad \forall j
\end{aligned}
$$

where $\mathrm{D}$ is the total demand, i.e. the sum of non participating loads (loads that would not be directly affected by any DSP programme) and potential participants that would not be eliminated by any DSP programme; $D^{*}$ is MW demand by potentially participating programs that would be eliminated if DSP measures are implemented. The constraints limit unit generation and the size of the DSP programme and cap is the capacity of generating unit $c$.

\section{Rate effects and value changes}

The above mechanism does not take into account the effect of costs on rates and loads. The costs estimated by the above model are fed into a financial mechanism that calculates rates according to a reward/penalty mechanism. If the resulting rates differ from those assumed in forecasting the loads in the reward/penalty mechanism, then those loads could be adjusted. Rate determination can be made internal to a model by adding a restriction, e.g. a revenue requirement equation (Braeutigam and Panzar, 
1993). This restriction specifies that the revenue received by the provider should cover its cost plus any consumer rewards that might be offered, for example, for pursuing DSP. For simplicity, the complications of multiple customer classes and nonlinear rate schedules will be ignored.

$$
P\left(Q-\sum_{j} D S P_{j}\right)=\left(k+\sum_{c} c_{c} G_{c}+\sum_{j} d_{u, j} D S P_{j}\right)
$$

Where $P$ is the price of electricity (expressed in $£ / \mathrm{MWh}$ ), $k$ is the capital and fixed operations and maintenance costs to be recovered from rates (in $£ / h$ ), and $Q$ is the potential MW load.

The left term in (7) is the provider's revenue and the right term is the provider's cost. It means that price times actual MWh load, equal to the potential load $Q$ minus savings due to DSP programs. Calculations related to rate-induced changes in loads are essential both for accurate estimates of the costs of serving those loads and to understand how these would affect the total value received by consumers.

\section{Weights for disadvantaged electricity consumers (physical and mobility disabilities, severe illness, number of dependent children)}

The incentive/payment scheme implies that consumers are tasked with the objective of improving the way they respond to price signals year by year. The pressure on active participation would be high on all types of consumers. However, the regulator might want to protect those consumers who for various reasons have limited ability to respond when it comes to shifting loads.

Weights should be included in the scheme to compensate the negative distributional impacts associated with the introduction of the incentive/payment scheme, particularly on disadvantaged electricity consumers. One of the criticalities of incentive-payment schemes is that they might increase disparities by penalising those who strive to pay energy bills. Elements of impedement to responsiveness (e.g. physical and mobility disabilities, severe illness, number of dependant children) could be factored into the mechanism: 


$$
\alpha_{\mathrm{t}}=\max \left[\beta \% ; 1-\left(\frac{\text { Meas }_{\mathrm{t}-1}{ }^{\frac{1}{\mathrm{z}+\mathrm{y}+\mathrm{x}}}}{\mathrm{Bn}_{\mathrm{t}-1}}\right)^{\frac{1}{\mathrm{t}}}\right]
$$

where $z$ is the disability rating, $y$ is the number of days per year of severe illness, and $x$ is the number of children per parent.

Although allocative efficiency is less tangible than productive efficiency, the introduction of weights for disadvantaged electricity consumers might be as important for the success of mechanism as rates charged for non-disadvantaged consumers.

\section{Mechanism simulation}

The relationship between $\operatorname{Meas}_{c, t}$ and price elasticity $\eta_{c, t}$ is given by

$$
\ln \left[1-\left(\frac{\mathrm{Meas}_{\mathrm{t}-1}{ }^{\frac{1}{\mathrm{z}+\mathrm{y}+\mathrm{x}}}}{\mathrm{Bn}_{\mathrm{t}-1}}\right)^{\frac{1}{\mathrm{t}}}\right]=\eta_{c, t}
$$

Mechanism simulations are run for three discrete levels of elasticity -based on UK implied price elasticities from Malpezzi and Maclennan (2001)- and retail electricity prices in the UK (IEA, 2011), which feed in to $C_{g e n}$ and $R_{t}$ as described in Equations (3) and (5).

The three elasticity levels are assumed to cover aggregate responses to similar conditions in prices, reflecting also key factors like weather conditions. The $\beta$ percentages vary depending on different segments of the residential sector. A standard econometric simulation software (Betahat) was applied. The different number of simulation runs is a consequence of the differences in number of observations associated with the timing of benchmarks setting and intervals for $\alpha_{t}$ levels. 


\begin{tabular}{ccccc}
\hline & & & & \\
& $\mathrm{Bn}_{\mathrm{t}}$ & $\left(\frac{\mathrm{Meas}_{\mathrm{t}-1} \frac{1}{\mathrm{z}+\mathrm{y}+\mathrm{x}}}{\mathrm{Bn}_{\mathrm{t}-1}}\right)^{\frac{1}{\mathrm{t}}}$ & $\mathrm{R}_{\mathrm{t}}$ & $\alpha_{\mathrm{t}}$ \\
\hline$\beta_{1, t}$ & 0.142 & -0.092 & 0.102 & -0.136 \\
& $(0.014)$ & $(0.012)$ & $(0.008)$ & $(0.009)$ \\
\hline$\beta_{2, t}$ & 0.146 & -0.025 & 0.014 & -0.044 \\
& $(0.026)$ & $(0.018)$ & $(0.028)$ & $(0.015)$ \\
$\beta_{3, t}$ & 0.090 & -0.025 & 0.031 & 0.020 \\
& $(0.033)$ & $(0.026)$ & $(0.019)$ & $(0.020)$ \\
$\beta_{4, t}$ & 0.089 & -0.004 & 0.007 & 0.003 \\
$\beta_{5, t}$ & $(0.020)$ & $(0.016)$ & $(0.014)$ & $(0.016)$ \\
& 0.057 & 0.018 & 0.019 & -0.012 \\
$\beta_{6, t}$ & $(0.028)$ & $(0.017)$ & $(0.015)$ & $(0.017)$ \\
Simulation & 0.194 & -0.033 & 0.057 & -0.027 \\
runs & $(0.043)$ & $(0.023)$ & $(0.012)$ & $(0.023)$ \\
\hline
\end{tabular}

Table 1 presents the mechanism run for negative elasticities $\left(\boldsymbol{\eta}_{\boldsymbol{c}, \boldsymbol{t}}=\mathbf{- 0 . 0 2}\right)$.

Findings show that non-responsive end-users are strongly penalised as demonstrated by negative $\alpha_{t}$ values in the last column to the right. A higher benchmark level $\left(B n_{t}\right)$ affects more strongly negative $\alpha_{\mathrm{t}}$ values. This reflects the fact that a higher performance is expected by those end-users who achieved higher levels of responsiveness in previous periods. The most evident example is from the comparison of $\boldsymbol{\beta}_{3, t}$ with $\boldsymbol{\beta}_{2, t}$. End-users who intentionally vary their performance throughout periods in order to gain from higher rewards will not be able to free-ride. This means that the opportunities for end-users to play with variations from one measurement period to the other is very limited as changes in $R_{t}$ control for the past performance. 


\begin{tabular}{ccccc}
\hline & & & & \\
& $\mathrm{Bn}_{\mathrm{t}}$ & $\left(\frac{\mathrm{Meas}_{\mathrm{t}-1}^{\frac{1}{\mathrm{z}+\mathrm{y}+\mathrm{x}}}}{\mathrm{Bn}_{\mathrm{t}-1}}\right)^{\frac{1}{\mathrm{t}}}$ & $\mathrm{R}_{\mathrm{t}}$ & $\alpha_{\mathrm{t}}$ \\
\hline$\beta_{1, t}$ & 0.122 & 0.033 & 0.121 & 0.005 \\
& $(0.011)$ & $(0.002)$ & $(0.013)$ & $(0.009)$ \\
$\beta_{2, t}$ & 0.116 & 0.010 & 0.072 & 0.003 \\
$\beta_{3, t}$ & $(0.020)$ & $(0.028)$ & $(0.032)$ & $(0.015)$ \\
& 0.011 & 0.009 & 0.051 & 0.031 \\
$\beta_{4, t}$ & $(0.031)$ & $(0.013)$ & $(0.020)$ & $(0.020)$ \\
$\beta_{5, t}$ & 0.072 & 0.024 & 0.031 & 0.013 \\
& $(0.016)$ & $(0.011)$ & $(0.016)$ & $(0.016)$ \\
$\beta_{6, t}$ & 0.074 & 0.018 & 0.019 & 0.023 \\
Simulation & $(0.035)$ & $(0.007)$ & $(0.013)$ & $(0.017)$ \\
runs & 0.187 & 0.012 & 0.041 & 0.057 \\
\hline
\end{tabular}

Turning to $\boldsymbol{\eta}_{\mathbf{c , t}}=\mathbf{0 . 1 6 9}$, parameter estimates in Table 2 are all positive and significantly different from zero at a one percent critical level. A higher overall elasticity condition is reflected by positive $\alpha$. This means that $\alpha$ t becomes positive when a higher number of end-users react to signals. For example, the at value of $\boldsymbol{\beta}_{5, \mathrm{t}}$ varies from -0.012 in Table 1 to 0.023 in Table 2 . The increments in Rt are more than proportional in comparison with negative elasticity levels, because planning costs marginally decrease. This is demonstrated, for instance, by the Rt value of $\boldsymbol{\beta}_{2, \mathbf{t}}$ which goes from 0.014 in Table 1 to 0.072 in Table 2. It should be noticed that the initial penalty reward level is very low. For the same levels of elasticity, a lower simulation run is associated with lower levels of $\alpha$ t. 


\begin{tabular}{ccccc}
\hline & & & & \\
& $\mathrm{Bn}_{\mathrm{t}}$ & $\left(\frac{\mathrm{Meas}_{\mathrm{t}-1}^{\frac{1}{\mathrm{z}+\mathrm{y}+\mathrm{x}}}}{\mathrm{Bn}_{\mathrm{t}-1}}\right)^{\frac{1}{\mathrm{t}}}$ & $\mathrm{R}_{\mathrm{t}}$ & $\alpha_{\mathrm{t}}$ \\
\hline$\beta_{1, t}$ & 0.121 & 0.021 & 0.111 & 0.006 \\
& $(0.012)$ & $(0.015)$ & $(0.017)$ & $(0.008)$ \\
$\beta_{2, t}$ & 0.118 & 0.023 & 0.053 & 0.004 \\
& $(0.015)$ & $(0.014)$ & $(0.029)$ & $(0.009)$ \\
$\beta_{3, t}$ & 0.015 & 0.015 & 0.053 & 0.026 \\
& $(0.027)$ & $(0.025)$ & $(0.031)$ & $(0.021)$ \\
$\beta_{4, t}$ & 0.045 & 0.051 & 0.023 & 0.020 \\
$\beta_{5, t}$ & $(0.012)$ & $(0.021)$ & $(0.018)$ & $(0.014)$ \\
& 0.064 & 0.015 & 0.021 & 0.021 \\
$\beta_{6, t}$ & $(0.037)$ & $(0.011)$ & $(0.011)$ & $(0.015)$ \\
Simulation & 0.095 & 0.013 & 0.052 & 0.061 \\
runs & $(0.031)$ & $(0.022)$ & $(0.029)$ & $(0.021)$ \\
\hline
\end{tabular}

Finally, the parameter estimates in Table 3 indicate that for high average elasticity $\left(\boldsymbol{\eta}_{\boldsymbol{c}, \boldsymbol{t}}=\mathbf{0 . 2 1 3}\right)$ the most responsive end-users significantly reduce bills thanks to high $\alpha_{t}$ levels associated with DSP planning. As expected, the measured consumer responsiveness for the previous period increases, while the benchmark levels for the previous period vary. For example, the $\left(\frac{\text { Meas }_{t-1} \frac{1}{B^{++y+x}}}{\mathbf{B n}_{t-1}}\right)^{\frac{1}{\mathbf{t}}}$ value of $\boldsymbol{\beta}_{1, t}$ decreases between Table 2 and Table 3, whereas the corresponding value for $\boldsymbol{\beta}_{\mathbf{2}, \boldsymbol{t}}$ increases in correspondence of higher elasticity levels.

The paper does not take into account the aggregated effect of all consumers' action. This is partly because the mechanism is designed to be run at the national level, with discrete users picked across the country, with limited interaction amd opportunities to influence each other's consumption behaviour. It is however useful, in addition to the quantitative simulation presented above, to reflect on some two borderline cases: first, that all end users respond to all signals at all times and, second, that no consumer respnds to any of the signals. The first case equates perfect elasticity (i.e. $\boldsymbol{\eta}_{\boldsymbol{c}, \boldsymbol{t}}=1$ ). 


\section{Conclusions}

The paper responds to the double need identified in the existing Demand Side Management literature to create sufficient incentives to providers for planning programs (Schultz and Lineweber, 2006) and to establish a regulatory framework to optimise the potential of DSP (Strbac, 2008). Unlike other existing rewards/penalty mechanisms which focus on the provider as the agent who should be incentivised to trigger DSP, the proposed mechanism is centred on consumers. It assumes that most of the capital costs associated with DSP have been (or will be) paid for as in the case of the smart metering roll-out in the UK. This paper has not addressed the question of what the best vehicle might be for putting the rewards and penalties into place and whether the mechanism is easy to understand. With regards to best vehicle, in principle, the payments and rewards should occur at the bill level. The information on how the mechanism works and the risks of higher bills could also be explained through bills prior to the implementation of the DSP program, as for instance happens in Italy with Time of Use tariffs (CRU, 2010). Whilst the epistemology of the mechanism developed in this paper is apparently rather complex, partly due to the integration of providers' costs, rate effects and value changes, its ontology is fairly uncomplicated. Consumers are expected to understand the bottom line, namely that if they manage to respond to peak signals they will pay lower bills, whereas if they fails to do so, they will have to pay higher bills. The effectiveness of the metering technology in putting across a peak signal, through e.g. lights, sounds etc, will certainly play a vital role in the understanding of the mechanism.

Incentive mechanisms can only be successful if they combine incentives for cost reductions with freedom on price balancing (Vogelsang, 2002). The effectiveness of the mechanism is likely to depend on the capacity of measuring consumption decreases following a peak signal. Existing models on time of use (see Richardson et al, 2008) suggest that monitoring of domestic consumption in 10 minute interval might be able to capture responses to signals. Further research is needed to establish what level of peak reduction (in $\mathrm{kWh}$ ) could be considered a sizeable response to the price signal. 
One of the criticalities of the DSP mechanism is the shift in risk for both providers and consumers. Providers will bear additional risks, because if their planning costs rise, their profits will fall because they cannot raise their prices to compensate for the cost increases. Only financially advantaged consumers might be able to benefit from the DSP mechanism and take the risk of paying higher bills for poor performance. One way to prevent the first criticality is to ensure that at consistent intervals (e.g. under the Price Control Review) the regulator reviews the objectives for the levels of rewards and penalties, as it occurs under the Quality of Supply regulation. In order to prevent the second criticality and encourage active demand participation of all residential consumers, while limiting volatility in the market and protecting 'weaker' consumers, objectives should be set so that different benchmarks should be applied to different consumers.

The highly electric low carbon future envisaged in UK energy and climate change policies (CCC 2008; UKERC 2009) implies that large portions of heat demand will largely be supplied by electricity. This will add considerably to the peaks in electricity demand unless DSP is implemented to shift these peaks to lower-demand times in the diurnal cycle. For instance, air source heat pumps add significantly to peak electricity demand because manufacturers typically install direct electric resistive backup heating in devices. According to the UK National Grid, peak demand in Britain is currently around 60GW. With air source heat pumps, peak demand in Britain is likely to increase by tens of GW. This is because the peak demand of a domestic heat pump will be around $7 \mathrm{~kW}$. The aggregate effect of heat pumps may be around $1.3 \mathrm{~kW}$ per home (Hawkes, 2010).

Finally, the mechanism presented in this paper assumes a completely new type of consumer. The "responsive" consumers will have their performance measured and will either save or pay depending on the improvements to their active DSP. Further research in the spheres of environmental psychology and sociology is needed to understand issues of acceptance of such mechanism and behavioural risks from a consumer perspective. 


\section{Acknowledgments}

The research leading to this paper was conducted as part of both the EPSRC/E.On supported Transitions project and the EPSRC supported Supergen FlexNet project.

\section{References}

Ajodhia, V., Lo Schiavo, L., and Malaman, R., 2006. Quality regulation of electricity distribution in Italy: an evaluation study. Energy Policy 34, 1478-1486.

Banfi, S., Farsi, M., Filippini, M., Jakob, M., 2008. Willingness to pay for energysaving measures in residential buildings. Energy Economics 30, 503-516.

Bartusch, C., Larsson, M., Wallin, F., Wester, L., 2010. Potential of Hourly Settlements in the Residential Sector of the Swedish Electricity MarketEstimations of Risk Reduction and Economic Result. International Journal of Green Energy 7, 224-240.

Bartusch, C., Wallin, F., Odlare, M., Vassileva, I., Wester, L., 2011. Introducing a demand-based electricity distribution tariff in the residential sector: Demand response and customer perception. Energy Policy 39, 5008-5025

Bilton, M., Ramsay, C., Leach, M. Devine-Wright, H., Devine-Wright, P., Kirschen, D, 2007. 'Domestic electricity consumption and demand side participation: opportunities and challenges for the UK power system'" in M. Grubb, T., Jamasb, Pollitt, M., (eds.) Delivering a Low Carbon Electricity System: Technologies, Economics and Policy. Cambridge: Cambridge University Press, 207-228.

Braeutigam, R., Panzar, J., 1993. Effects of the change from rate-of-return regulation to price-cap regulation. American Economic Review 83, 191-198.

CCC, 2008. Building a low carbon economy - The UKs contribution to tackling climate change: The First Report of the Committe on Climate Change. Climate change Committee.

CRU (2010) La tariffa bioraria, quando conviene e consigli per il mercato libero accessed at http://www.centroconsumatori.tn.it/download/141dextn5N1Ch.pdf on $\underline{1 \text { st May } 2011}$

Decanio, S., and Laitne, J., 1997. Modeling technological change in energy demand forecasting: A generalized approach. Technological Forecasting and Social Change $55,249-263$.

Dulleck, U., Kaufmann, S., 2004. Do customer information programs reduce household electricity demand? - The Irish program. Energy Policy 32, 1025-1032. 
Faruqui, A., George, S., 2005. Quantifying Customer Response to Dynamic Pricing. Electricity Journal 18, 53-63.

Faruqui, A., Hledik, R., Sergici, S., 2010. Rethinking prices: The changing architecture of demand response in America. Public Utilities Fortnightly 148, 3039.

Fisher, C., 2005. On the importance of the supply side in demand-side management. Energy Economics 27, 165-180.

Hawkes, A., 2010. Low Carbon Residential Heating. Woring paper. Grantham Institute for Climate Change. Imperial College London, UK.

Hunt, L. 2003. Underlying trends and seasonality in UK energy demand: a sectoral analysis. Energy Economics 25, 93-118.

International Energy Agency, 2011. Monthly energy prices. IEA.

Littlechild, S., 2003. Reflections on incentive regulation. Review of Network Economics 2, 289-315.

Malpezzi, S., Maclennan, D., 2001 The Long-Run Price Elasticity of Supply of New Residential Construction in the United States and the United Kingdom Journal of Housing Economics 10, 278-306.

Nomura, N., Akai, M., 2004. Willingness to pay for green electricity in Japan as estimated through contingent valuation method. Applied Energy, 78, 453-463.

Richardson, I., Thomson, M., Infield, D., 2008. A high-resolution domestic building occupancy model for energy demand simulations. Energy and Buildings 40, 15601566.

Sibley, S., 1989. Asymmetric information, incentives and price-cap regulation. RAND Journal of Economics 20, 392-404.

Schultz, D., Lineweber, D., 2006 Real Mass Market Customers React to Real TimeDifferentiated Rates: What Choices Do They Make and Why? 16th National Energy Services Conference. San Diego, CA. February 2006.

Strbac, G., 2008. Demand side management: Benefits and challenges. Energy Policy, $36,4419-4426$.

Torriti, J., Hassan, M., Leach, M., 2010. Demand response experience in Europe: Policies, programs and implementation. Energy 35, 1575-1583.

UKERC, 2009, UKERC Energy 2050 Making the transition to a secure and lowcarbon energy system: synthesis report. UK Energy Research Centre.

Vogelsang, I., 2002. Incentive regulation and competition in public provider markets: a 20-year perspective. Journal of Regulatory Economics 22, 5-27. 
Wirl, F., 1995. Impact of regulation on demand side conservation programs. Journal of Regulatory Economics 7, 43-62.

Wiser, R. H. 2007. Using contingent valuation to explore willingness to pay for renewable energy: A comparison of collective and voluntary payment vehicles. Ecological Economics 62, 419-432. 